\title{
Da positivação à significação da
}

\section{universalização: uma análise sobre o direito à vida no ordenamento jurídico Brasileiro a partir das contribuições dos Direitos Internacionais dos Direitos Humanos}

\section{From positivization to the meaning of universalization: an analysis of the right to life in the Brazilian legal system based on the contributions of International Human Rights Law}

\author{
Thiago Allisson Cardoso de Jesus ${ }^{1}$ \\ Luiz Guilherme Luz Cardoso ${ }^{2}$
}

\begin{abstract}
Resumo: O presente artigo analisa a positivação do Direito à Vida no Ordenamento Jurídico Brasileiro, a partir da ótica apresentada pelos tratados, convenções e declarações dos Direitos internacionais dos Direitos Humanos ratificados pelo Brasil. O problema central gira em torno da seguinte questão: Qual foi a contribuição dos tratados de Direitos Humanos à positivação do Direito à vida, tal como apresentado pelo ordenamento jurídico brasileiro e em que medida repercutiu para a universalização desse direito? A pesquisa possui natureza exploratória, faz abordagem qualitativa e faz uso das técnicas de pesquisa documental, bibliográfica e análise de conteúdo. Objetiva-se a compreensão do sentido atribuído ao Direito à vida, a partir da positivação e significação empregada pelos Direitos Humanos e contribuir com a literatura especializada, bem como fomentar novas práticas, mentalidades e discursos acerca da proteção e regulação jurídica sobre a vida.
\end{abstract}

Palavras-chave: Vida. Positivação. Significação. Regulação. Universalização.

\footnotetext{
${ }^{1}$ Pós-Doutorando em Direitos Humanos pela Universidade de Salamanca, Espanha. Pósdoutor pelo Programa de Pós-Graduação em Ciências Criminais da Escola de Direito da Pontifícia Universidade Católica (PUC/RS). Pós-doutor em Desigualdades Globais e Justiça Social: diálogos Sul e Norte pela Faculdade de Direito da UnB. Doutor em Políticas Públicas pela Universidade Federal do Maranhão (2017). Mestre em Políticas Públicas (2012) pelo PGPP/UFMA. Especialização em andamento em Compliance pelo Instituto de Direito Penal Econômico da Universidade de Coimbra. Professor Adjunto I do Curso de Direito da Universidade Estadual do Maranhão (UEMA) e da graduação em Direito e pós-graduação em Ciências Criminais em Direito e em em Direito e Afirmação de Vulneráveis na Universidade Ceuma.

2 Acadêmico de Direito da Pontifícia Universidade Católica de Campinas (2017-2021). Estagiário de Direito da Defensoria Pública do Estado de São Paulo em Campinas (2020Atual). Bolsista de Iniciação Científica do Fundo de Apoio à Iniciação Científica FAPIC/Reitoria da PUC CAMPINAS (2019-2020). Conciliador Estadual do Juizado Especial Cível - JEC Campinas (2019). Bolsista do Programa Santander Graduação (2018-2019).
} 


\begin{abstract}
This article analyzes the positivization of the Right to Life in the Brazilian Legal System, from the perspective presented by the treaties, conventions and declarations of international human rights rights ratified by Brazil. The central problem revolves around the following question: What was the contribution of Human Rights treaties to the positivization of the Right to life, as presented by the Brazilian legal system and to what extent did it have repercussions for the universalization of this right? The research has an exploratory nature, makes a qualitative approach and makes use of documentary, bibliographic and content analysis techniques. The objective is to understand the meaning attributed to the Right to life, based on the positivation and significance used by Human Rights and to contribute to the specialized literature, as well as to foster new practices, mentalities and discourses about the protection and legal regulation of life.
\end{abstract}

Keywords: Life. Positivation. Meaning. Regulation. Universalization.

\title{
1. Introdução
}

O princípio da inviolabilidade do Direito à vida encontra-se positivado no título II dos Direitos e Garantias Fundamentais, caput do artigo $5^{\circ}$ da Constituição da República Federativa do Brasil. Esse direito precede ao exercício de qualquer outro e a Constituição fez questão de protegê-lo com primazia e, a partir dele, revelou tantos outros como a liberdade, a integridade moral e física, igualdade, segurança e a propriedade.

Do mesmo modo, a legislação infraconstitucional, em especial o Código Penal Brasileiro reservou um capítulo específico intitulado "Dos Crimes contra a vida" para apontar os tipos penais e as penas cominadas a cada infração que possa violar a vida humana.

Em continuação, o Código Civil Brasileiro (2002), estabeleceu em seu Art. $2^{\circ}$ que a vida é pressuposto à aquisição da personalidade jurídica, e o Art. $7^{\circ}$ do Estatuto da Criança e do Adolescente (1990) trouxe um conceito mais abrangente de vida, entendida como "direito social ou material que origina obrigação de fazer" (FERRAJOLI, 2006, p. 794).

Assim, como se não bastasse à positivação do Direito à vida na Carta Magna de 1988, o ordenamento jurídico brasileiro como um todo e em represália aos acontecimentos históricos de escravidão e ditaduras não só 
elegeu a vida como direito fundamental, mas a consagrou como um "prérequisito à existência e exercício de todos os demais direitos" (MORAIS, 2003, p. 63).

Mas, afinal qual é a definição de Direito à Vida? Segundo a lição de LUCIANA RUSSO (2009, p. 91), “o direito à vida é o bem mais relevante de todo ser humano e a dignidade da pessoa humana é um fundamento da República Federativa do Brasil e não há dignidade sem vida”. Ou seja, mais do que um Direito, a vida é um bem relevante considerado um pressuposto básico para a dignidade humana, uma vez que a dignidade na linguagem da autora não subsiste sem a vida.

No âmbito dos Direitos Internacionais dos Direitos Humanos, o Direito à Vida nem sempre foi reconhecido como um Direito. Somente a partir da Segunda Guerra Mundial, conhecida por suas torturas e tratamentos degradantes aos prisioneiros, surgiram às declarações, convenções e acordos que possibilitaram a proteção à vida humana e, por conseguinte, a condenação à pena de morte.

Tal proteção se positivou com a ascensão da Declaração Universal dos Direitos Humanos (1948), marco histórico que consagrou em seu Art. $3^{\circ}$ o direito à vida. Depois dessa, cita-se a Convenção Americana sobre Direitos Humanos (1978), que também consagrou o Direito à vida no Art. $4^{\circ}$ acrescido da complementação do Art. $5^{\circ}$ que inaugurou o Direito à integridade pessoal como efetivação do Direito à vida.

No mais, o Brasil é signatário tanto da declaração, quanto da convenção, além de outras convenções que serão explicitadas no decorrer na pesquisa. Por essa razão, e na ânsia de verificar as contribuições dos Tratados e Convenções no ordenamento Jurídico Brasileiro para a consolidação e positivação do Direito à vida, é que se dedica o artigo. Para tanto, a pesquisa objetiva analisar as contribuições dos Direitos Internacionais dos Direitos humanos à positivação/significação do Direito à vida tal como apresentado pelo ordenamento jurídico Brasileiro. 
Inicialmente se realizou o levantamento das normas convencionais e demais documentos normativos que tratam a temática do Direito à Vida no âmbito dos Direitos Humanos. Posteriormente, o levantamento das normas constitucionais e infraconstitucionais do ordenamento Jurídico Brasileiro. Por último, perscrutou-se a evolução de conceitos, e as relações e proximidades entre os Direitos Internacionais dos Direitos Humanos e o Direito Brasileiro na positivação do Direito à vida.

Tal pesquisa, inserida no campo da ciência do Direito, adota a perspectiva hermenêutica que reconhece a plurivocidade do texto jurídico, identificando a norma como resultada da interpretação. Ou ainda, uma "versão discursiva” (HESPANHA, 2009 p. 654/657). Para a abordagem do objeto de estudo, vale-se, então, das técnicas de pesquisa documental, da análise de conteúdo, pressupondo apuradas técnicas de pesquisa bibliográfica. Por meio da pesquisa documental, foram levantadas e sistematizadas as normas convencionais do Direito Internacional dos Direitos Humanos (sistema global e interamericano) e ordenamento jurídico brasileiro normas constitucionais e infraconstitucionais.

Com a análise de conteúdo (BARDIN, 2011), foi possível a averiguação dos Tratados, Convenções e documentos da ONU que versam sobre a matéria a fim de sistematizar as contribuições para a positivação do Direito à Vida tal como se encontra na Constituição Federal do Brasil.

Destarte, a pesquisa apresentar-se-á a partir de um intenso plano de investigação, a saber, das subseções: (I) A vida qualificada como um Direito Fundamental; (II) Da construção à positivação do Direito à vida no plano universal: Levantamento dos Tratados documentos e convenções que versam sobre a matéria. (III) O Direito à Vida no Ordenamento Jurídico Brasileiro: Levantamento das normas constitucionais e infraconstitucionais. Ao final, considerações representativas sobre o tema ora investigado.

\section{Do direito fundamental à vida e a sua efetivação.}


O Direito à vida encontra-se explicitado no quadro de Direitos Fundamentais apresentados pela Constituição Federal do Brasil de 1988. Tais Direitos estão agrupados em cinco capítulos, quais sejam direitos individuais e coletivos, direitos sociais, direitos da nacionalidade, direitos políticos e direitos atinentes à participação em partidos políticos.

Mas afinal, o que são os Direitos Fundamentais? Na lição de (PINHO, 2002, p. 65), Direitos Fundamentais podem ser definidos como àqueles:

Indispensáveis à pessoa humana, necessários para assegurar a todos uma existência digna, livre e igual. Não basta ao Estado reconhecê-los formalmente; deve buscar concretizá-los, incorporálos no dia-a-dia dos cidadãos e de seus agentes.

José Afonso da Silva realça o conceito ao identificar nos direitos fundamentais um conteúdo de essencialidade. Segundo ele, a melhor terminologia seria a de direitos fundamentais do homem, pois,

(...) no qualificativo fundamental acha-se a indicação de que se trata de situações jurídicas sem as quais a pessoa humana não se realiza, não convive e, às vezes, nem mesmo sobrevive; fundamentais do homem no sentido de que a todos, por igual, devem ser, não apenas formalmente reconhecidos, mas concreta e materialmente efetivados. (AFONSO. 2012, p. 182).

Com o advento da Declaração Universal dos Direitos Humanos, o Direito à vida assumiu um novo patamar classificatório sendo citado no primeiro grupo dos Direitos individuais. Por este motivo, grande parte da doutrina confunde Direitos Humanos com garantias e direitos Fundamentais. No entanto, àqueles são consagrados em um plano internacional, exteriorizados nas convenções e tratados. Já os direitos fundamentais são positivados em determinado ordenamento jurídico de uma comunidade política.

Nesse sentido, se o Direito à vida no plano internacional é um Direito Humano, no plano nacional ele assume a natureza de Direito Fundamental 
cuja titularidade é atribuída a todos, brasileiros ou não, como preceitua o caput do Art. $5^{\circ}$ da Constituição Federal de 1988:

Art. $5^{\circ}$ Todos são iguais perante a lei, sem distinção de qualquer natureza, garantindo-se aos brasileiros e aos estrangeiros residentes no País a inviolabilidade do direito à vida, à liberdade, à igualdade, à segurança e à propriedade. (Brasil, 1988).

Desse modo, para a garantia do Direito à vida o ordenamento jurídico brasileiro preferiu tratar este Direito dentro do capítulo dos Direitos Fundamentais como reação ao contexto ditatorial da constituição antecessora e a histórica violação de direitos atrelados a existência humana. Como se não bastasse ter elevado tal direito a categoria de fundamental, a Constituição de 1988 atribuiu a "brasileiros e estrangeiros" no caput do Art. 5, contribuindo para a universalização do Direito à vida que precede inclusive os direitos de nacionalidade, tamanho o seu caráter fundamental.

Ademais, o Direito à vida, tal como se conhece positivado pela Constituição em sua característica fundamental, necessita de políticas governamentais ao alcance da eficácia vertical que a defenda em todos os estágios do desenvolvimento humano, desde a fecundação até a morte natural, bem como produza eficácia horizontal que consista na qualidade de vida do ser humano, envolvendo o direito à saúde, assistência social, meio ambiente equilibrado dentre outros.

Nessa toada, a Declaração Universal dos Direitos Humanos (1948) consagrou em seu Art. 25 a eficácia horizontal do Direito à Vida, nesses termos:

1. Todo ser humano tem direito a um padrão de vida capaz de assegurar a si e à sua família saúde, bem-estar, inclusive alimentação, vestuário, habitação, cuidados médicos e os serviços sociais indispensáveis e direito à segurança em caso de desemprego, doença invalidez, viuvez, velhice ou outros casos de perda dos meios de subsistência em circunstâncias fora de seu controle.

2. A maternidade e a infância têm direito a cuidados e assistência especiais. Todas as crianças, nascidas dentro ou fora do matrimônio, gozarão da mesma proteção social. (UNICEF, 1948). 
Destarte, não basta à positivação do direito, ou o seu reconhecimento em caráter "fundamental", é necessário à sua efetivação que, com base em Ramos (2014,) alcança-se por meio de três grandes obrigações estatais, a saber: a) A obrigação de respeito: As autoridades estatais não devem violar a vida de outrem; b) Obrigação de garantia: Proteger a vida do indivíduo contra atos de terceiros e a consequente punição dos seus violadores; c) A obrigação de Tutela: Oferecer uma vida digna, assegurando-se as condições mínimas de existência do indivíduo.

\section{Da construção à positivação do Direito à Vida no plano universal: Levantamento dos tratados, documentos e convenções que versam sobre a matéria.}

Com o cenário pós-segunda guerra mundial, os países envolvidos presenciaram inúmeras atrocidades, torturas e tratamentos degradantes aos condenados - prisioneiros e civis. Por esta razão, despertou-se o desejo universal de positivar em tratados, pactos, acordos e convenções o Direito à Vida como expressão máxima de contra-ataque as constantes violações.

Até então, o Direito à vida era considerado apenas uma concepção de proteção isolada em alguns países, atrelado à ideia de proteção aos territórios e a integridade física, o que não era marcado pela universalização. Contrapondo a essa ideia regionalista do Direito à Vida, insurge no plano mundial a Declaração Universal dos Direitos humanos de 1948 que estabeleceu:

Art. III. Toda pessoa tem direito à vida, à liberdade e à segurança pessoal.

Art. V. Ninguém será submetido à tortura nem a tratamento ou castigo cruel, desumano ou degradante.

Perceba que a declaração na ânsia de preservar a vida não apenas assegura o direito; visa também proibir comportamentos de tortura, castigo cruel, desumano ou degradante. Subentende-se, muito embora o texto normativo não tenha demonstrado expressamente com a menção a 
instituições ou órgãos, que os países signatários a esta Declaração deverão desdobrar-se para o alcance efetivo da tutela e proteção ao Direito à vida.

Ainda no plano Universal, dentre as declarações em que o Brasil figura-se como signatário, vale citar a Declaração e Programa de Ação de Viena (1993) que estabelece para o progresso duradouro necessário à realização do direito ao desenvolvimento, políticas eficazes em nível nacional, bem como relações econômicas equitativas e um ambiente econômico favorável em nível internacional. Assim preceitua o Art. 11:

O direito ao desenvolvimento deve ser realizado de modo a satisfazer equitativamente as necessidades ambientais e de desenvolvimento de gerações presentes e futuras. A Conferência Mundial sobre Direitos Humanos reconhece que a prática de descarregar ilicitamente substâncias e resíduos tóxicos e perigosos constitui uma grave ameaça em potencial aos direitos de todos à vida e à saúde.

Muito embora, o excerto preserve o Direito à Vida, atrelado à temática do descarregamento de substâncias e resíduos tóxicos, tal dispositivo representa importante avanço ao resignificar a vida a partir dos parâmetros de desenvolvimento, sendo a aquela a finalidade última do deste. No âmbito do Sistema Interamericano de Proteção aos Direitos Humanos, a Declaração Americana (1948) regulou a temática do Direito à vida em seus Artigos, I e V respectivamente:

Todo ser humano tem direito à vida, à liberdade e à segurança de sua pessoa.

Toda pessoa tem direito à proteção da lei contra os ataques abusivos à sua honra, à sua reputação e à sua vida particular e familiar.

Da mesma forma que as declarações anteriores, o direito à vida é apresentado com preponderância em relação aos outros direitos, acrescido da inovação do Art. V que transfere ao legislador à responsabilidade de criar leis que assegurem à proteção a vida particular.

Passa-se a análise dos Tratados Internacionais ratificados pelo Brasil no que pertine a proteção ao bem jurídico aqui em comento. Em análise 
cronológica, insta frisar a Convenção Relativa ao Estatuto dos Refugiados (1951) que no Art. 33, intitulado "Proibição de expulsão ou de rechaço", impõe aos Estados partes algumas obrigações, dentre elas:

Nenhum dos Estados Contratantes expulsará ou rechaçará, de maneira alguma, um refugiado para as fronteiras dos territórios em que a sua vida ou a sua liberdade seja ameaçada em virtude da sua raça, da sua religião, da sua nacionalidade, do grupo social a que pertence ou das suas opiniões políticas.

Note que o artigo em apreço impõe aos Estados contratantes o dever de proteção, pois, ainda que o refugiado tenha sua pátria, o país em que ele se encontra jamais poderá enviar o refugiado sob o fundamentado no argumento do país de origem, se este for causa de ameaça a dois direitos humanos e fundamentais: Vida e liberdade.

Já na década de 60, destaque ao Pacto Internacional dos Direitos Econômicos, Sociais e Culturais (1966). Este, por sua vez, apresenta o Direito à Vida a partir da perspectiva horizontal, que incluiu outros direitos como (alimentação, vestimenta e moradia), ao alcance do que mais tarde será conhecido como "Vida digna" (SARLET, 2008, p. 34-35). Preceitua o Art. 11 do citado pacto (1966):

\footnotetext{
Os Estados-partes no presente Pacto reconhecem o direito de toda pessoa a um nível de vida adequado para si próprio e para sua família, inclusive à alimentação, vestimenta e moradia adequadas, assim como uma melhoria contínua de suas condições de vida. Os Estados-partes tomarão medidas apropriadas para assegurar a consecução desse direito, reconhecendo, nesse sentido, a importância essencial da cooperação internacional fundada no livre consentimento.
}

Na contramão, a apresentação genérica do Direito à Vida, já citado pela Declaração Universal (1948), sobrevém nas proximidades da década de 70 a partir da Convenção Americana de Direitos Humanos (1969), com a adesão de 25 repúblicas, ficou conhecida como "Pacto de San José da Costa Rica”, estabelece:

Artigo $4^{\circ}$ - Direito à vida 
1. Toda pessoa tem o direito de que se respeite sua vida. Esse direito deve ser protegido pela lei e, em geral, desde o momento da concepção. Ninguém pode ser privado da vida arbitrariamente.

2. Nos países que não houverem abolido a pena de morte, esta só poderá ser imposta pelos delitos mais graves, em cumprimento de sentença final de tribunal competente e em conformidade com a lei que estabeleça tal pena, promulgada antes de haver o delito sido cometido. Tampouco se estenderá sua aplicação a delitos aos quais não se aplique atualmente.

3. Não se pode restabelecer a pena de morte nos Estados que a hajam abolido.

4. Em nenhum caso pode a pena de morte ser aplicada a delitos políticos, nem a delitos comuns conexos com delitos políticos.

5. Não se deve impor a pena de morte à pessoa que, no momento da perpetração do delito, for menor de dezoito anos, ou maior de setenta, nem aplicá-la a mulher em estado de gravidez.

6. Toda pessoa condenada à morte tem direito a solicitar anistia, indulto ou comutação da pena, os quais podem ser concedidos em todos os casos. Não se pode executar a pena de morte enquanto o pedido estiver pendente de decisão ante a autoridade competente.

Artigo $5^{\circ}$ - Direito à integridade pessoal

1. Toda pessoa tem direito a que se respeite sua integridade física, psíquica e moral.

2. Ninguém deve ser submetido a torturas, nem a penas ou tratos cruéis, desumanos ou degradantes. Toda pessoa privada de liberdade deve ser tratada com o respeito devido à dignidade inerente ao ser humano.

3. A pena não pode passar da pessoa do delinquente.

4. Os processados devem ficar separados dos condenados, salvo em circunstâncias excepcionais, e devem ser submetidos a tratamento adequado à sua condição de pessoas não condenadas.

5. Os menores, quando puderem ser processados, devem ser separados dos adultos e conduzidos a tribunal especializado, com a maior rapidez possível, para seu tratamento.

6. As penas privativas de liberdade devem ter por finalidade essencial a reforma e a readaptação social dos condenados.

A partir destes dois artigos, torna-se perceptível que a Convenção abordou o Direito à Vida de modo mais preciso resguardo-o tanto aos naturais quanto aos estrangeiros.

Com a proteção à vida desde a concepção, o direito é estendido ao embrião rompendo o silêncio dos tratados que a antecedeu, vez que estes não se expressarem acerca do início da vida. Para, além disso, o texto impulsionou o ordenamento jurídico de muitos países a exemplo do Código Civil brasileiro (2002) que resguarda no seu Art. 2 os Direitos do nascituro. No mais, a respectiva Convenção determina condições à pena de morte, 
permitindo-a somente nos casos de delitos mais graves em que houver sentença de órgão colegiado (tribunal), proibindo seu reestabelecimento nos países em que fora abolida, não permitindo que a pena afete crianças e maiores de sessenta anos (considerando o risco de fragilidade), bem como mulheres grávidas (mais uma vez a proteção ao nascituro).

Tal positivação foi considerada ao seu tempo um grande progresso, pois não permitia que os Estados pactuantes dispusessem sobre o Direito à Vida, elevando-o a condição de direito indisponível, irrenunciável e inalienável, como se verifica no Art. 27:

A disposição precedente não autoriza a suspensão dos direitos determinados nos seguintes artigos: 3 (direito ao reconhecimento da personalidade jurídica), 4 (direito à vida), 5 (direito à integridade pessoal) [...].

Por esta razão, o Direito à Vida - mesmo quando iminente a situação de Perigo Público, guerra ou outra emergência - não poderá ser mitigado ou sofrer qualquer retaliação justificado nesses três estados.

Em 1987, não menos importante, e a título de complementação dos Artigos supracitados, sobrevém a Convenção sobre os Direitos da Criança (1978). O Direito à Vida é tratado com homogeneidade, sendo o mais elementar e absoluto dos direitos indispensáveis para o exercício dos demais. Distinguindo-se de "sobreviver", pois o atual estágio de evolução exige vida com dignidade, assim prevê os artigos respectivos:

Artigo $6^{\circ}$ - 1. Os Estados - partes reconhecem que toda criança tem $\mathrm{o}$ direito inerente à vida.

Artigo 37 - Os Estados - partes assegurará que:

Nenhuma criança seja submetida a tortura nem a outros tratamentos ou penas cruéis, desumanos ou degradantes. Não será imposta a pena de morte, nem a prisão perpétua, sem possibilidade de livramento, por delitos cometidos por menores de dezoito anos de idade.

Nesse sentido, a Criança foi agraciada, pois teve seu direito à vida, bem como a proteção a integridade física, assegurados pelos Estados partes, 
tutela não garantida antes. Transferiu-se para cada país signatário o desejo do legislador universal pela criação e imposição de leis que promovessem não apenas a vida, mas a qualidade dessa vida, capaz de promover a dignidade humana.

Em síntese, devido ao fenômeno da universalização da proteção do Direito à vida, a garantia a existência tornou-se um imperativo de sobrevivência para toda humanidade.

\section{O Direito à Vida no Ordenamento Jurídico Brasileiro:} Levantamento das normas constitucionais e infraconstitucionais.

Consoante Rocha (2019), até a Constituição dos Estados Unidos do Brasil de 1946 não era possível identificar dispositivos que pudessem expressar diretamente a proteção ao Direito fundamental à vida da forma como fez a Constituição de 1988. Esta, além de reconhecê-lo como direito humano fundamental, elevou os Direitos Humanos à categoria de norma constitucional obstando o processo para modificação destes. A par dessa garantia, o Direito à Vida ficou resguardado contra qualquer ato que pudesse dispor ou revogar sua positivação.

Desse modo, ante as controvérsias doutrinárias e jurisprudenciais acerca da hierarquia dos tratados internacionais de direitos humanos no ordenamento brasileiro, a Emenda Constitucional $\mathrm{n}^{\circ} 45$ de dezembro de 2004 acrescentou um $3^{\circ}$ parágrafo ao artigo $5^{\text {o }}$ determinando:

\footnotetext{
Os tratados e convenções internacionais sobre direitos humanos que forem aprovados, em cada Casa do Congresso Nacional, em dois turnos, por três quintos dos votos dos respectivos membros, serão equivalentes à emenda constitucional.
}

Ao encontro da Emenda Constitucional referida, o Supremo Tribunal Federal inovou tal entendimento quando julgou o Recurso Extraordinário 


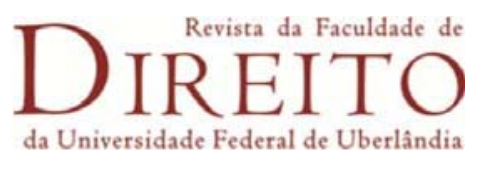

466.343 - $1 \mathrm{SP}^{3}$ e conferiu status de norma supralegal aos Tratados Internacionais, ou seja, o STF entendeu que os tratados estão acima da lei ordinária, mas abaixo da Constituição.

Em seu Art. $5^{\circ}$, a Constituição garante a inviolabilidade do Direito à vida, tanto aos brasileiros, quanto aos estrangeiros. O ilustre doutrinador Tavares (2010), ao comentar os direitos fundamentais a partir da ordem apresentada pela Constituição, faz questão de dizer que o direito à vida:

É o mais básico de todos os direitos, no sentido de que surge como verdadeiro pré-requisito da existência dos demais direitos consagrados constitucionalmente. É, por isto, o direito humano mais sagrado.

No mais, é interessante perceber que a Constituição vigente ao apresentar o Direito à vida no rol dos Direitos Fundamentais, não apenas conferiu "status", mas incentivou todo ordenamento a pensar o direito à vida nessa perspectiva. A título de exemplo, vale citar o disposto na Constituição Estadual do Estado do Rio de Janeiro, que em seu Art. 8, parágrafo único transferiu ao Estado o dever de garantir, não só a vida como fez o legislador constituinte, a qualidade de vida, ao assim ressaltar:

Art. $8^{\circ}$ Todos têm o direito de viver com dignidade. Parágrafo
único. É dever de o Estado garantir a todos uma qualidade de vida
compatível com a dignidade da pessoa humana, assegurando a
educação, os serviços de saúde, a alimentação, a habitação, o
transporte, o saneamento básico, o suprimento energético, a
drenagem, o trabalho remunerado, o lazer, as atividades
econômicas e a acessibilidade, devendo as dotações orçamentárias
contemplar preferencialmente tais atividades, segundo planos e
programas de governo.

Ou seja, muito embora o Direito à vida, considerado por muitos doutrinadores pré-requisito à aquisição dos demais direitos fosse uma

3 O status normativo supralegal dos tratados internacionais de direitos humanos subscritos pelo Brasil, dessa forma, torna inaplicável a legislação infraconstitucional com ele conflitante, seja ela anterior ou posterior ao ato de ratificação. (STF: RECURSO EXTRAORDINÁRIO: 466.343- 1SP. Relator: Ministro: Cesar Peluso. Dj. Disponível em: http://www.stf.jus.br/imprensa/pdf/re466343.pdf. Acesso em 04. fev. 21. 
realidade do legislador originário, tal Direito se ramificou aos legisladores estaduais (ordinários) na forma de dever, mais precisamente de dever de efetivação.

Ainda sobre a influência do Art. $5^{\circ}$ caput da Constituição de 1988 no que concerne ao Direito à vida, o legislador ordinário em matéria de Direito Civil (2002), tratou no Título "Das pessoas naturais" no Art. 2०: "A personalidade civil da pessoa começa do nascimento com vida; mas a lei põe a salvo, desde a concepção, os direitos do nascituro”.

Nascituro entendido como o ser já concebido, mas que ainda se encontra no ventre materno, segundo a definição de Silvio Rodrigues:

\begin{abstract}
A lei não lhe concede personalidade, a qual só lhe será conferida se nascer com vida. Mas, como provavelmente nascerá com vida, o ordenamento jurídico desde logo preserva seus interesses futuros, tomando medidas para salvaguardar os direitos que, com muita probabilidade, em breve serão seus. (RODRIGUES, 2016 p. 34).
\end{abstract}

Além disso, existe no Código Civil brasileiro um sistema de proteção ao nascituro, com as mesmas conotações conferidas a qualquer ser dotado de personalidade. Desse modo, é obrigatória a nomeação de um curador, se o pai falecer estando grávida a mulher, e não tendo esta o poder familiar, conforme preceitua o art. 1.779; pode o nascituro ser objeto de reconhecimento voluntário de filiação (art. 1.609, parágrafo único); pode receber doação (art. 542) e ser contemplado em testamento (art. 1.798), dentre outros direitos.

Na mesma linha de raciocínio, o Código Penal (1940) assegurou aos Nascituros o Direito à vida coibindo o aborto em algumas circunstâncias, a saber:

Aborto provocado pela gestante ou com seu consentimento:

Art. 124. Provocar aborto em si mesmo ou consentir que outrem lhe provoque:

Pena - detenção, de um a três anos.

Aborto provocado por terceiro:

Art. 125. Provocar aborto, sem o consentimento da gestante: 
Pena - reclusão, de três a dez anos.

Art. 126. Provocar aborto com o consentimento da gestante:

Pena - reclusão, de um a quatro anos.

Parágrafo único. Aplica-se a pena do artigo anterior, se a gestante não é maior de quatorze anos, ou é alienada ou débil mental, ou se o consentimento é obtido mediante fraude, grave ameaça ou violência.

Forma qualificada

Art. 127. As penas cominadas nos dois artigos anteriores são aumentadas de um terço, se, em consequência do aborto ou dos meios empregados para provocá-lo, a gestante sofre lesão corporal de natureza grave; e são duplicadas, se, por qualquer dessas causas, lhe sobrevém à morte.

Veja que o Código penal preferiu tratar o aborto no Título dos crimes contra a vida, pois o legislador ordinário reconheceu no feto a qualidade de ser vivente, punindo não somente a gestante que provocou o aborto, mas o terceiro que incentivou tal prática. Nesse diapasão, o legislador qualificou o crime de aborto na hipótese em que a gestante sofrer lesão corporal de natureza grave com resultado de morte, e reconheceu o caráter de duplicidade das penas para a modalidade qualificada, ou seja, subjetivamente se reconhecia dois bens jurídicos atingidos: A vida da gestante, bem como a vida do feto.

No mais, e em se tratando de vulneráveis, vale citar duas grandes leis a começar pelo Estatuto da Criança e do Adolescente. Este apresentou o Direito à vida concomitante ao Direito à saúde no capítulo reservado aos Direitos fundamentais. Nesse ponto, como um "microssistema jurídico o Estatuto criou mecanismos de amparo e proteção à criança, e ao adolescente, garantindo-lhes instrumentos efetivos de Defesa” (ISHIDA, 2019, p. 52).

$\mathrm{O}$ referido Estatuto preceitua no Art. $7^{\circ}$ o Direito à vida, inspirado pelo Art. $6^{\circ}$ da Convenção sobre os direitos da criança de 1989, o citado inovou, pois acrescentou no texto normativo, não somente à vida, mas a sua efetivação por meio de políticas sociais públicas, desenvolvimento e condições dignas de existência, assim fez constar: 
Art. $7^{\circ} \mathrm{A}$ criança e o adolescente têm direito a proteção à vida e à saúde, mediante a efetivação de políticas sociais públicas que permitam o nascimento e o desenvolvimento sadio e harmonioso, em condições dignas de existência.

Segundo (ISHIDA. 2019 p. 51), as políticas sociais públicas "podem ser entendidas como o conjunto de ações desencadeadas pelo Estado, na esfera federal, estadual e municipal com vistas ao atendimento do bem coletivo". Como preceitua o Art. $70^{\circ}$-A, caput: Art. 70- A:

A União, os Estados, o Distrito Federal e os Municípios deverão atuar de forma articulada na elaboração de políticas públicas e na execução de ações destinadas a coibir o uso de castigo físico ou de tratamento cruel ou degradante e difundir formas não violentas de educação de crianças e de adolescentes.

Ou seja, cabe ao Estado à elaboração de tais políticas, não só, como preceitua o Art. $70^{\circ}$ (do citado Estatuto), "é dever de todos previr a ocorrência de ameaça ou violação dos direitos da criança e do adolescente".

No mesmo sentido, a lei 11.340/2006, conhecida como "Lei Maria da Penha" protegeu outra categoria vulnerável em seu direito à vida: as mulheres contra qualquer ato de violência doméstica e familiar. Para tanto, dissertou:

Art. $3^{\circ}$ Serão asseguradas às mulheres as condições para o exercício efetivo dos direitos à vida, à segurança, à saúde, à alimentação, à educação, à cultura, à moradia, ao acesso à justiça, ao esporte, ao lazer, ao trabalho, à cidadania, à liberdade, à dignidade, ao respeito e à convivência familiar e comunitária.

Art. 11. No atendimento à mulher em situação de violência doméstica e familiar, a autoridade policial deverá, entre outras providências:

III - fornecer transporte para a ofendida e seus dependentes para abrigo ou local seguro, quando houver risco de vida;

Art. 12-C. Verificada a existência de risco atual ou iminente à vida ou à integridade física da mulher em situação de violência doméstica e familiar, ou de seus dependentes, o agressor será imediatamente afastado do lar, domicílio ou local de convivência com a ofendida.

Evidente por meio da análise, que os dispositivos trouxeram a baila uma proteção integral ao Direito à vida da mulher, não verificada 
anteriormente, assegurou desde a fase pré - processual de registro da ocorrência, até a efetivação da tutela protetiva o resguardo da vida, seja na locomoção da mulher até a delegacia, seja no afastamento do cônjuge ou companheiro que lhe cause ameaça ou risco de vida eminente.

Desse modo, os dispositivos da lei Maria da Penha evidenciaram que a tutela antes conhecida por sua característica genérica "todos têm Direito à vida" ganhou um novo status protetivo, uma vez que o legislador inovou ao pensar no processo de respaldo jurídico à mulher ameaçada e violentada, a partir das condições sociais, afetivas e psicológicas de quem pleiteia proteção.

Por meio deste apanhado geral do ordenamento jurídico brasileiro em matéria de positivação do Direito à vida foi possível perceber que o direito perquirido pelo constituinte originário revestiu-se de diferentes interpretações a partir do conteúdo apresentado pelas leis ordinárias, àquilo que era genérico, tornou-se específico para atender ao maior desafio: efetivar o primeiro e o de maior densidade normativa, a Vida.

\section{Considerações finais}

A partir da análise dos Tratados e Convenções Internacionais, bem como das normas constitucionais e infraconstitucionais, foi possível compreender a evolução do Direito à vida em diferentes planos. Através da comparação e sistematização dos supramencionados artigos, pode-se concluir que o Direito Internacional dos Direitos Humanos contribuiu à significação do direito à vida pelo ordenamento jurídico brasileiro nos seguintes termos:

1. Universalização do Direito à vida: Com a criação da Organização das Nações Unidas em 1945 e o surgimento da Declaração Universal dos Direitos humanos em 1948, iniciou-se a universalização do Direito à vida. Esse fenômeno contribui e incentivou o legislador constituinte de 1988, pois, como é notório pela leitura e interpretação do 
Art. 5 caput da Constituição Federal, o estrangeiro foi enxergado como sujeito de direito à vida, impondo ao Estado brasileiro o dever de proteção, sem distinção, e como se não bastasse assegurar-lhe a vida, tal garantia abriu precedentes ao reconhecimento e salvaguarda dos demais direitos como: Liberdade, igualdade, segurança e propriedade.

2. Direito Humano Fundamental à vida: Após a promulgação do Direito à vida no Art. $3^{\circ}$ da Declaração Universal dos Direitos Humanos (1948), esse direito foi recepcionado pela Constituição Brasileira de 1988 da forma como apresentado pela declaração mantendo-se inclusive a mesma sequência, porém com o acréscimo de dois outros: Igualdade e propriedade. Por conseguinte, o constituinte originário reconheceu a significação da vida como direito inerente ao ser humano, mais do isso, impulsionado pela Declaração criou um capítulo exclusivo para a custódia dos intitulados "Direitos Fundamentais", que são Direitos Humanos no plano universal, porém com a terminologia "fundamental", própria do formalismo empregado pela Constituição para se referir aos direitos que não podem ser alterados, ou modificados por livre disposição do legislador.

3. Proteção dos vulneráveis em seu Direito à vida: A proteção do Direito à vida tornou-se específica (no que diz respeito às políticas de proteção) somente com o advento da Convenção Americana sobre Direitos Humanos promulgada em 1969. Até então, o que os organismos internacionais protegiam era tão somente à vida, sem apontar diretrizes de proteção, ou quem sabe, imposições aos Estados signatários.

Pela análise do Art. 4 da referida Convenção tornou-se perceptível uma maior proteção que se estendeu ao feto (desde a concepção), e contra toda e qualquer ameaça imposta pela pena de morte, não aplicada em nenhuma hipótese para menores de 18 anos, maiores de 60 anos e mulheres grávidas.

A Convenção influenciou e contribuiu no plano nacional para a criação de estruturas específicas de proteção à vida, ao transferir aos Estados a 
obrigação de respeito e garantia. Vale citar o exemplo de algumas leis, e seus respectivos artigos: a) Do Art. 2 do Código Civil de 2002, inserido no capítulo "Dos Direitos da Personalidade", que em sua positivação reconheceu os direitos do nascituro; b) Do Art. $7^{\circ}$ do Estatuto da Criança e do Adolescente que preceitua a vida e a saúde, sendo este último à efetivação daquele, o Art. $70^{\circ}$ e $70^{\circ}$ - A, do citato Estatuto que transferiu a todos e ao Estado o dever de coibir violações ao Direito à vida, da forma como fez o Art. $1^{\circ}$ da Convenção; c) Do Art. $3^{\circ}$ da Lei Maria da Penha, uma vez que os citados direitos: à vida, à segurança, à saúde, à alimentação [...], já eram muito antes uma realidade assegurada pela Convenção.

Em síntese, a Convenção (1969) contribuiu para a efetiva proteção do nascituro, da mulher, da criança e do idoso, grupos considerados vulneráveis, em suas qualidades e capacidades de garantir o livre exercício do Direito à vida.

\section{Referências}

BARDIN, Laurence. Análise de conteúdo. Trad. L. A. Reto e A. Pinheiro. São Paulo: Edições 70, 2011.

BRASIL. Constituição do Estado do Rio de Janeiro. Disponível em: http://alerjln1.alerj.rj.gov.br/constest.nsf/PageConsEst?OpenPage. Acesso em: 06. fev.2021.

BRASIL. Decreto - Lei $\mathrm{n}^{\circ}$ 2.848, 07 dezembro de 1940. Código Penal. Disponível em: http://www.planalto.gov.br/ccivil_03/decreto-lei/del2848compilado.htm. Acesso em: 06. fev. 2021.

BRASIL. Lei $\mathrm{n}^{\circ}$ 10.406, 10 de janeirio de 2002. Código Civil. Disponível em: http://www.planalto.gov.br/ccivil_03/leis/2002/110406compilada.htm. Acesso em: 06. fev. 2021.

BRASIL. Lei $\mathrm{n}^{\circ}$ 11.340, de 7 de agosto de 2006. Lei Maria da Penha. Disponível em: http://www.planalto.gov.br/ccivil_03/_ato2004-2006/2006/lei/111340.htm. Acesso em: 06. fev. 2021.

BRASIL. Lei $\mathrm{n}^{0}$ 8.069, de 13 de julho de 1990. Estatuto da criança e do adolescente. Disponível em: http://www.planalto.gov.br/ccivil_03/leis/18069.htm. Acesso em: 06. fev.2021. BRASIL. Constituição. 1988. Constituição da República Federativa do Brasil. Brasília, DF: Centro Gráfico, 2017.

CONVENÇÃO Americana de Direitos Humanos. 1969. Disponível em: http://www.pge.sp.gov.br/centrodeestudos/bibliotecavirtual/instrumentos/sanjose.htm.

Acesso em: 05. fev. 2021. 


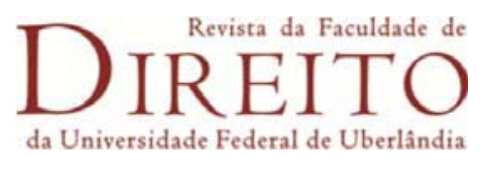

CONVENÇÃO Relativa ao Estatuto dos Refugiados. 1951. Disponível em: https://www2.camara.leg.br/legin/fed/decret/1960-1969/decreto-50215-28-janeiro-1961389887-publicacaooriginal-1-pe.html. Acesso em: 04. fev. 2021.

CONVENÇÃO sobre os Direitos da Criança. 1987. Disponível em: https://www.unicef.org/brazil/convencao-sobre-os-direitos-da-crianca. Acesso em: 05.fev.2021.

DECLARAÇÃO Americana dos Direitos e Deveres do Homem. 1948. Disponível em: http://pfdc.pgr.mpf.mp.br/atuacao-e-conteudos-de-apoio/legislacao/direitos-

humanos/declar_dir_dev_homem.pdf. Acesso em: 03. fev. 2021.

DECLARAÇÃO e Programa de Ação de Viena. 1993. Disponível em: http://www.pge.sp.gov.br/centrodeestudos/bibliotecavirtual/instrumentos/viena.htm. Acesso em: 03. fev. 2021.

DECLARAÇÃO Universal dos Direitos Humanos. 1948. Disponível em: https://www.unicef.org/brazil/declaracao-universal-dos-direitos-humanos. Acesso em: 02. fev. 2021.

FERRAJOLI, Luigi. Direito e razão, teoria do garantimos penal. 2. Ed. São Paulo: Revista dos Tribunais 2012.

HESPANHA, António Manuel. O caleidoscópio do direito: o direito e a justiça nos dias e no mundo de hoje. Coimbra: Almedina, 2009, p. 654/657.

ISHIDA, Valter Kenji. Estatuto da criança e do adolescente doutrina e Jurisprudência. Doutrina e Jurisprudência. 2019, p. 52.

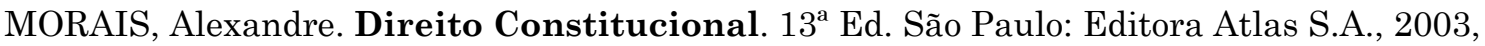
p. 63.

PACTO Internacional dos Direitos econômicos sociais e culturais. 1966. Disponível em: http://www.planalto.gov.br/ccivil_03/decreto/1990-1994/d0591.htm. Acesso em: 05. fev. 2021.

PINHO, Rodrigo César Rebello. Teoria geral da Constituição e direitos fundamentais. 3.ed. rev. São Paulo: Saraiva, 2002.p.65. v.17.

RODRIGUES, Silvio. Código Civil. Parte Geral. 2016 p. 34. Disponível em: https://direitouninovest.files.wordpress.com/2016/04/silvio-rodrigues-direito-civil-partegeral-1.pdf. Acesso em 05. Fev. 2021.

RUSSO, Luciana. Direito Constitucional. $2^{a}$ Ed. São Paulo: Editora Saraiva 2009, p. 91. SARLET, Ingo Wolfgan. Dignidade da pessoa humana e direitos fundamentais na Constituição Federal de 1988. 6. ed. Porto Alegre: Livraria do Advogado, 2008. p. 34-35.

SILVA, José Afonso. Curso de Direito Constitucional Positivo. São Paulo: Malheiros, 2012.

TAVARES, André Ramos. Curso de Direito Constitucional. $8^{\text {a }}$ Ed. São Paulo: Editora Saraiva 2010, p. 569. 